Epiphany: Vol. 7, No. 1, 2014

ISSN 1840-3719

\title{
Theory, Literature, and Dialogue: Bakhtinian Consciousness in New Indian Literature
} Bhumika Sharma*

\begin{abstract}
Emerging new literature has facilitated a dialogue among the alternative aesthetics created by new literature with an interpolation of central theoretical discourses. It opens an avenue for theories travelling across cultures to decipher intricacies involved into contemporary world. Today we live with a global consciousness that illustrates the formulation of a new postcolonialpostmodernist 'I'. Bakhtin's concepts of dialogic consciousness, the unfinalizable self and the idea of the relationship between the 'self' and 'others' lead us to understand this postcolonial-postmodernist framework as reflected in many Indian literary and cultural discourses. It throws light on how we perceive an individual entity in relation to the specific socio-cultural code which inhere multiple intercessions. Present article attempts to discover the fundamentals of the 'postcolonial-postmodernist liberation' through the case study of two selected Indian literary texts by Arvind Adiga and Amitav Ghosh. Both the texts explain the psychology behind the working of dialogic consciousness and the intercession involved in the formulation of postcolonialpostmodernist subject. It may be elucidated through the understanding of mechanism that always strives to attain a point of equilibrium. Representing the postcolonial-postmodernist psychology which questions various cultural norms, it initiates a dialogue between freedom and restrictions, individual and social, and real versus virtual. It turns out an everlasting quest for refined version of the metamorphic 'self' shaped by the dialogic consciousness of the postcolonial and postmodernist world.
\end{abstract}

Keywords: Dialogic Consciousness; Unfinalizable 'self'; New Literature; Theoretical Intercession; Postcolonial-postmodernist Psychology

\footnotetext{
* Corresponding author: Bhumika Sharma, Assistant Professor, Central University of Rajasthan, Bandar Sindri, Ajmer Rajasthan, India; e-mail: sharmabhumika@curaj.ac.in
} 
The vast realm of emerging new literature opens an avenue for theories travelling across cultures to decipher intricacies involved into contemporary world. Today we live with a global consciousness that shape our psychology. Theorists have given us many analytical tools to understand the differences and diversities of the $21^{\text {st }}$ century postmodernist and postcolonial world. It has facilitated a new dialogue among the alternative aesthetics created by new literature with an interpolation of central theoretical discourses. Does it illustrate a new postcolonial-postmodernist flux that indicates a complex dialogic embrace between theory and literature? How does such interlacing comprehend subtle implications of cultural crisscross? In fact, it designates a new psychological paradigm which elucidates various postcolonial and postmodernist developments.

\section{Defining Contemporariness}

In a glimpse, our contemporariness appears a curious combination of east and west, real and virtual, and a process of redefining 'centres' in relation to the 'margins'. Being a part of the hi-tech multicultural global world, we experience these juxtapositions at every moment. The world seems to be constituted of images drawn from different sources. Holding so many differences together a postcolonial-postmodernist understanding strives to negotiate multiple 'others' with reference to one's defined spatialtemporal positioning. It is the key term 'difference' that underlies every 'post' theory mosaic. All postmodernist compositions whether at physical or at metaphysical level, are acknowledged as

\footnotetext{
Epiphany: Journal of Transdisciplinary Studies, Vol. 7. No. 1, (2014) @ Faculty of Arts and Social Sciences
} 
well as absorbed with a typical psychological bend to the underlying idea of 'difference' that resists the process of homogenisation at the same time facilitating a reasonable covert acceptance of it. Each response to the prevailing multiplicities of postmodernist time is regulated by the interactive action taking place in the negotiating zone. In fact, it is the irresistible negotiation among various differences that constitutes the key element of postmodernist psychology. It works both at individual and collective level especially when an entity undergoes the process of identity formulation.

\section{A Dialogic Zone: Bakhtin's Theoretical Explanation of Negotiating Differences}

Bakhtin's concepts like carnival, heteroglossia, and polyphony help to explain the nature of contemporary culture where one may find oneself engaged in an everlasting dialogue within and without. Perhaps, it is the compulsive human instinct of negotiating differences that generates a dialogic consciousness. Every individual, being a unit, constitutes merely a part of the whole. Yet, on the other hand, existing as an independent entity one also strives to attain completeness in oneself. In this process of self attainment the dialogic consciousness assumes central role, formulating a typical tendency of talking to 'self' with regard to the fragmented 'others' around.

Negotiating differences is a very important term when we open an explorative chapter on postcolonial and postmodernist psychology. Since living in today's era means living with

\footnotetext{
Epiphany: Journal of Transdisciplinary Studies, Vol. 7. No. 1, (2014) @ Faculty of Arts and Social Sciences
} 
differences and dissensions, the validity of any kind of uniform coding appears susceptible. With the postmodernist mode of thinking the idea of 'absolute' crumbles. Monologue gives way to dialogue and we acknowledge the dialogic consciousness as an inherent feature of human sensibility. The historical consciousness which underlies the vast literary and cultural discourses of human civilisation reinterprets the strategic relationship between the differentiating 'twos' of binary opposition. With the increasing dialogue 'twos' break down into 'many' debilitating all the boundaries that create them. It questions the foundational principles of various categorisations that define our contemporariness.

\section{Intercessional Working of Postcolonial-postmodernist Psychology}

How do we perceive the conception of identity especially with regard to today's postcolonial and postmodernist position? Do we all collectively inhabit the world as an assortment of individuals living in continuous flux? Since the idea of any stable identity founded on original purity does not hold true in the world of multiple centres engaged in continuous dialogue, the process of identity formulation becomes more complex. Identifying oneself with such state of incomplete 'self' endorses Bakhtin's conception of unfinalizable 'self'. It substantiates the strong imminence of negotiation, here predominantly with respect to the scattered 'others' the 'self' chooses to interact with in the postmodernist world of 'differences'. It calls for an intercessional mode of

\footnotetext{
Epiphany: Journal of Transdisciplinary Studies, Vol. 7. No. 1, (2014) @ Faculty of Arts and Social Sciences
} 
working in human psyche. What is important to understand the constitution of postmodernist psychology is to identify this intercessional form, i. e., the nature of bargain and the level of intensity at which socio-political or cultural negotiations are worked out at different levels of human sensibility.

While investigating the issue harbouring on Bakhtin's idea of dialogic consciousness, one can easily recognise the multiplicity of perspective and voices and the possibility of their cohabitation at borderline. But there exist two levels of dialogic consciousness where negotiations are enacted in the process of identity formation especially in relation to the postmodernist condition of multiple 'others.' How it is worked out anticipates a layered exposition of the consciousness. In view of the complexities involved in a two tier visualisation of human consciousness, one's enquiry of intercessional working need to be conducted separately, in a phased manner. Since it is the two dimensional expansion of the 'self' which brings out the attributive difference between the individual and collective consciousness and its characterisation of intercessional working of the postcolonialpostmodernist psychology.

At the level of individual consciousness it is the dialogic 'self' that undergoes the process of identity formulation making itself responsible for the negotiation. Being the double edged postcolonial-postmodernist 'self' it, a priori, acknowledges the presence of 'others' for address and engagement. Its dialogue with multiple others necessarily anticipates closure, notwithstanding 
how short lived and unfinalizable, but a closures that anticipates the next level of closure making it an ongoing process.

On the other hand, the postmodernist collective consciousness, while engineered with the post-national outlook of postcolonial framework, appears more inclined to erase the borderlines. It passes by the first stage celebration of postcolonial national identity paving the way to global consciousness through a network of statements and responses. In its incomplete and unfinalizable expression it continuously rejects the authoritative discourses to respect the existing world in its autonomy generating a dialogue in which all socio-cultural components are forced to participate for more truthful version of postcolonialpostmodernist reality.

Who Am I? The Postcolonial-postmodernist 'Self' in Dialogue Human psyche conceives the 'differences' with ambivalence. The 'difference' creates the idea of 'other' and the 'other' is always seen an object of embrace as well as resistance. Present postcolonial and postmodernist phase definitely blurs, if not erases completely, the boundaries existing between the categorised constructions of different nature. These realities manage to coexist on account of peculiar psychology of embracing the 'Others' while relieving the apprehensions of losing 'Self' through dialogic consciousness. Since it is a vital question that how far one allows the 'other' to be accommodated as a part of the 'self' while negotiating differences, one needs to understand the nature of such barter at every level of consciousness. Perhaps, there is a dicey borderline drawn by each 
one of us in the process of resolving inner and outer contradictions.

I am conscious of myself and become myself only while revealing myself for another, through another, and with the help of another. The most important acts constituting selfconsciousness are determined by a relationship toward another consciousness (toward a thou) ... The very being of man (both external and internal) is the deepest communion. To be means to communicate ... To be means to be for another, and through the other for oneself. A person has no internal sovereign territory, he is wholly and always on the boundary: looking inside himself, he looks into the eyes of another or with the eyes of another ... I cannot manage without another, I cannot become myself without another. (287)

The above quoted expression of 'the self' reveals the importance of 'other' in the formation of one's identity. Whatever 'I' expresses is always out of its dialogue with 'other' as well as its response to the 'other'. As pointed out by Martin Irvin, in Bakhtin's view,

an expression in a living context of exchange--termed a "word" or "utterance"--is the main unit of meaning. It is formed through a speaker's relation to Otherness, that is to say, other people, others' words and expressions, and the lived cultural world in time and place.

The postcolonial-postmodernist dialogue of the 'self' consists of many such expressions. It occurs both at inner and outer stratum since the postmodernist psychology inheres the internalisation of 'other' in the 'self' as an ongoing process of identity formulation. Situated at the hinge, the conversation may take place within the 'self'. One is the speaker as well as the listener. Who speaks here on behalf of the 'self' as the postcolonial-postmodernist condition does not leave any place for 
original purity? Is it the 'Other Voice' experienced within the 'self'? Does it represent those 'others' picked up by the 'I' from the outside world. Perhaps, it is the same 'other' existing in the world without, but knowingly or unknowingly, internalised as a part of the 'self'. It may be denominated variedly, call it the voice of conscience, or internalised stereotypes, absorbed ideologies or to be more scientific, the domain of human psyche termed 'superego' by Freud in his theory of psychoanalysis. In simpler terms it is the inner resistance or the acquiescence that rein the flight of the 'self' giving it desired direction in response to the question "Who am I?" The answer to this question can never be monologic. It is always an outcome of inner dialogic consciousness that confers upon the 'singularity' to each individual through a distinct identity to the 'self' despite sharing numerous common features with others.

Illustrating the Composition of Rare 'I' in Adiga's The White Tiger

Let's probe into the formation of a combinative 'rarity' that marks the duality of postcolonial-postmodernist consciousness. It consists in choosing the assumptions that suits to the desired liberation of the 'Self'. The postcolonial-postmodernist 'Self' appears a proportionate composition of various selections of what one would like to be. Textual analysis of Adiga's celebrated work The White Tiger demonstrates how it is worked out through a dialogic consciousness. According to Bakhtin, the 'I' cannot maintain neutrality toward moral and ethical demands which manifest themselves as one's voice of consciousness. Freud' 
classification of Id, Ego and Superego also refers to the same while explaining the structure of psychological sections that rift apart the 'self' exhibiting a clash between natural drives and social obligations. Yet, it is an accepted dictum that one owes to his own feelings and sentiments. An individual is always committed to the liberation of its 'self'. While confronting any 'Other' that liberates the 'Self' from the pressure of such demands, the 'self' moves out from already defined territory. It is drawn to embrace the 'Other' that attracts it for being unconventional, or unfamiliar, or the 'different'. It seems alluring on account of its liberalising impact. But such lead is always full of apprehension of dismembering the 'self' or robbing of its unity. Post modernist psychology frees the 'self' from such apprehensions facilitating a free dialogue. Since the postmodernist world of mosaic multiplicities offers one immense possibilities to drift from the accustomed 'self' through a dialogic process, the intercessions become less restrictive and more open, as well as intense and regular both at internal and outer levels. The 'self' is free to negotiate with multiple 'others' in its constant reification. It facilitates one's liberation revising the points of equilibrium attained through dialogic consciousness that constantly shapes the transformed ' $\mathrm{I}$ '. Being charged with a fascination to attain completeness, the 'self' always remains dialogic. Bakhtin's concepts of the unfinalizable self and the idea of the relationship between the self and others help us to understand this postcolonial-postmodernist psychology. It's reflection in Adiga's The White Tiger becomes apparent when the reader discovers its 
protagonist engaged in a continuous dialogue which subscribes to the formulation of his identity. Whether addressed to the Chinese premier or enacted in his own mind, the protagonist of the novel exposes a dialogue at work, working out the new 'Self' of its protagonist Balram. Balram is the emergence of new ' $I$ ' as a postmodernist individual, at the same time, facilitating the IndoChinese dialogue of collaborative Asian understanding against colonial west. What Balram attains at postmodernist level reinforces the postcolonial resistance and denial to neocolonialism.

Adiga christians Balram the white tiger for being rare. What makes him 'rare'? Doesn't the narrative evince that it is Balram himself who bequeaths rarity to his 'self'. He rejects all the prior definitions imposed upon him by various class and caste metanarratives. Same holds true for new third world power like India and China. He represents the true postmodernist construction where meta-narratives crumple down giving way to a significant micro narrative generated out of his dialogue with the organic world around him. It is the dialogue between these two that makes him rare since Balram's uninhibited dialogic consciousness endorses the postcolonial-postmodernist psychology of disbelief in fixed definitions.

Adiga's white tiger may be treated as an interesting case study of postcolonial-postmodernist psychology of intercession. The rarity of Balram exhibits how we can perceive each individual in relation to the specific socio-cultural code. Each 'self' in postmodernist condition is rare on account of its 
combinative quality. It reiterates postcolonial rhetoric of a new negotiated multicultural identity founded on global consciousness. Postcoloniality is an ever evolving dialogue with the west. As the dialogue never closes permanently, multi-layered intercessions reify the self, keeping it always in flux and for that matter, anticipating further and, in fact, continuous transformation. As a postcolonial-postmodernist construction Balram epitomises affirmation and negation of dialogic consciousness executed by the 'self' as it suits to it in its response to other. It is executed at the level of both person and nation in today's postcolonialpostmodernist world. Since the postmodernist displacement of meta- narratives with multiple micro narratives evinces loosening of the conceptions like ethics, morality and many such impositions, postcolonial designates the liberated nationalist assumption within reconstructed global liberation. As a sign of it, one can easily experience how to let the other permeate into or release it from one's 'self' when engaged in dialogue.

It, in a way, explains the psychology behind the working of dialogic consciousness. Comprehended through the mechanism that always strives to attain a point of equilibrium, postcolonialpostmodernist psychology demonstrates an intersection between yeas and nays. What determines the identity of the 'self' in question is the attainment of that point, how so ever momentary. Let's see how it works in the case of Balram who reveals his dialogic consciousness in the following expression:

One day at a traffic signal, the driver of the car next me lowered the window and spat out: he had been chewing paan, and a vivid red puddle of expectorate splashed on the hot midday road and festered there like a living thing, spreading 
and sizzling. A second later, he spat again-and now there was a second puddle on the road. I stared at the two puddles of red, spreading spit- and then:

The left-hand puddle of spit seemed to say:

Your father wanted you to be an honest man.

Mr. Ashok does not hit you or spit on you, like people did to your father.

Mr. Ashok pays you well, 4,000 rupees a month. He has been raising your salary without your even asking.

Remember what the buffalo did to his servant's family. Mr. Ashok will ask his father to do the same to your family once you run away.

\section{But the right-hand puddle of spit seemed to say:}

Your father wanted you to be a man.

Mr. Ashok made you take the blame when his wife killed that child on the road.

This is a pittance. You live in a city. What do you save? Nothing.

The very fact that Mr. Ashok threatens your family makes your blood boil.

I turned my face away from, the red puddles. I looked at the red bag sitting in the centre of my rearview mirror, like the exposed heart of the Honda City. (Adiga, Pg. 245-46)

It is the cleft in the 'self'. It is the part of the 'self' trying to shed the ideological burdens of ethics and morality imposed upon it by socio-political norms. These norms anticipate each to follow the rules laid down for classified group or social stratum that structure the system. Certain well defined behaviour pattern is expected from each one to make the system work. 'Self' is pressurised to follow the normative lines that identifies one's 'self' with a particular class or categorisation. Only that makes one fit in the system. Balram was planning to murder his master for no apparent personal consciously done mistake by him. Now what matters most is to understand how far his innocent master resembles the innocent neo-colonial hegemony. This pretended 
innocence is to be exterminated for the realisation of a truly liberated 'Self'. So, it was his psychological need to justify his intended act otherwise how will he define his 'self' in the light of his acts. It reminds well known African American artist Richard Wright's seminal work Native Son the protagonist of which also undergoes the same dialogic process in defining himself in the context of outside world. Such dialogue consists of what he thinks of himself in response to what others think of him. He also undertakes the liberation of 'self' which inheres a dialogic nature talking to itself and finding who's, why's and how's of the happenings. How can he justify his present action with special reference to the injustices done to his 'self' in the past? The internal quietening extends to the world without, turning into a passionately heated dialogue with the society. The author himself appears intensely engaged in the dialogue raising the question if it is possible to find out an ideological solution of racial debate prevalent in America.

Adiga's white tiger Balram resembles Wrtight's native son Bigger since both exemplifies the dialogic consciousness of the 'self' that defines it. Their dialogue within the 'self' represents a well composed heteroglot. Whether it is $20^{\text {th }}$ century American Bigger or $21^{\text {st }}$ century Indian Balram, their 'self' consists of various voices from different sources, be it social, political, economic, religious, moral or ethical institution of the society. The difference simply lies in the focus and intentionality of the dialogue that dramatises its fictional representation in the text. In Wright's case it is racial oppression whereas Adiga picks up the 
class conflict underlying the contemporary capitalistic democracy of a developing third world. Both of them bring out the psychological underpinnings that shape the behaviour pattern of human character.

Bakhtin's concept of dialogic imagination helps to explain the postcolonial-postmodernist psychology of conflicting ideas that simultaneously dwell in consciousness driving the individual 'self' into different directions. Since the postcolonialpostmodernist world is seen as a fragmented whole, an individual mind turns into a fragmentary composition of ideas. There is neither certainty nor finality. Values change with the time; meaning alters with the place; and the text varies with the context since there is no meta-narrative to supply the defined norms. It is the epoch of multiple micro narratives involved in a never ending dialogue. The postcolonial-postmodernist 'self' absorbs this dialogue placing itself in relation to the multiple 'others' that shape today's multicultural, multi-linguistic, multi- religious, and multi-ethical society.

\begin{abstract}
And finally, at any given moment, languages of various epochs and periods of socio-ideological life cohabit with one another... Thus at any given moment of its historical existence, language is heteroglot from top to bottom: it represents the coexistence of socio-ideological contradictions between the present and the past, between differing epochs of the past, between different socio-ideological groups in the present, between tendencies, schools, circles and so forth, all given a bodily form... Therefore languages do not exclude each other, but rather intersect with each other in many different ways. (Dialogic Imagination, Pg. 291)
\end{abstract}

In the context of The White Tiger Adiga's protagonist finds it difficult to obliterate the voice of past existing in his 
consciousness in the form of his father's image and words spoken by him. But he has to resolve the debate to ensure a concrete action. Decision is to be taken in either/or and it is important since it is closely associated with the question of the liberation of the 'self' from multiple others imposed upon the consciousness of Balram. In the words of Bakhtin, "The word lives, as it were, on the boundary between its own context and another, alien, context." (Dialogic Imagination, Pg. 284).

Balram's dialogic imagination differentiates between 'honest man' and 'man' in a subtle manner. In the perception of his 'self' an honest man can never become a man given the relative position of his 'self' to the 'others'. He makes the language of his 'self' an instrument to express his dissension with his defined status and role. It is very much required for its liberation. He constructs a different and contextualised meaning in his expression to himself since the 'addressivity' and 'answerability' both lie in one's own perception. It is his own self that engages in the conversation with itself, hence the meaning is to be constructed as well as understood from two different stands.

Neutral dictionary meanings of the words of a language ensure their common features and guarantee that all speakers of a given language will understand one another, but the use of words in live speech communication is always individual and contextual in nature. (Speech Genres and Other Late Essays p.88)

An author uses various narrative techniques to bring in the dialogic consciousness of the 'self'. Sometimes it takes the form of interior monologue and at other times it simply flows along the stream of consciousness embroiled in the inner thoughts and 
opinions of the person in question. Whatever the case, it ultimately exhibits the acceptance and rejection of the 'other' by the 'self'.

There is adequate complexity in postmodern fiction of the 1980 s and 1990s to trace those internal dialectics of complicity and immanent critique without anticipating some 'unimaginable new mode of representation' which will somehow make it all easier for us. (The Fiction of Postmodernity, p. 56)

Perhaps, it illustrates the complexity of the postcolonialpostmodernist 'self' reflected in the fictional works of post 1950s Indian literary tradition.

\section{Postcolonial-postmodernist Deconstruction: Towards a Borderless World}

Besides the negotiations of macro and micro narratives enacted in the multilayered consciousness of the postcolonialpostmodernist self, the intercessional psychology is to be understood at the level of collective consciousness too. Since it is the shared sensibilities that give birth to typical inclinations and collective responses, one is required to decipher the formation of group identity. How are the group identities formed? Are these fully proportional to the erection or corrosion of various sociopolitical constructs? Caused by the emergence of new sensibilities, and performed at community level, indeed these are always subject to altercation. The changed perception of the postcolonial-postmodernist world serves as a demonstration of its deconstructive nature which makes it conducive to the notion of ever changing space-time continuum.

\footnotetext{
Epiphany: Journal of Transdisciplinary Studies, Vol. 7. No. 1, (2014) (C Faculty of Arts and Social Sciences
} 
To test the validity of the argument let's take up a case study of the novel The Shadow Lines (1988) penned down by the IndianBengali writer Amitav Ghosh. The novel brings out the intricacies of the deconstructive psychology that shapes the virtual reality of the contemporary world. In this world one finds it hard to demarcate the 'real' and 'virtual'. Founded on the conception, the novel exquisitely illustrates Bakhtin's questioning of the significance or non-significance of borderlines. Demarcation always anticipates division, and division leads to dialogue. Does the dialogue generated out of civilizational coding and categorised divisions manifest the working of postmodernist collective consciousness? Since the dialogue anticipates a connection, its possibility right away ruptures the idea of segmentation implied in all kind of divisions. Constant blurring of the boundaries through such dialogic consciousness explicates the postcolonialpostmodernist move from local to global. The image of the global citizen represents an all inclusive collective identity. It reflects the cumulative projection of a fractured identity caught in the precariousness of negotiating zone.

Ghosh's novel The Shadow Lines interlaces the life of a young boy growing up in Calcutta and later on in Delhi and London. The narrator adores Tridib because of his tremendous knowledge and his perspective of the incidents and places. He loves listening to Tridib because Tridib's lore is very different from the collection of facts and figures. Narrator's grandmother called Tha'mma has a dreadful past and wants to reunite her 
family and goes to Dhaka to bring back her uncle. Later Tridbib gets killed by frenzied mob in the communal riots of 1963-64 in Dhaka in his attempt to rescue her love May.

The novel aptly epitomises the cleft experienced in the new global world emerging out of postcolonial-postmodernist sensibility. Those who live that experience pass through a dilemma of being placed between local and global. The postcolonial-postmodernist reality of the world marked with an implicated diasporic consciousness shatters the unity of nationalist identity codified in the 'self' in terms of political geography. It is the part of the consciousness that identifies the elements of national as well as cultural 'otherness'. How does the postcolonial-postmodernist self react to it? What experience does it undergo? It is interestingly captured in the broodings of the narrator of The Shadow Lines, whose narration captures the dialogic consciousness. The novel evinces the disjointed perspective of time and events, of lines that bring people together and hold them apart, lines that are clearly visible from one perspective and nonexistent from another, Lines that exist in the memory of one, and therefore in another's imagination and so on. The author seems to believe that these are the lines that fragment the unified 'self' of an individual. The postcolonial-postmodernist psychology lies in questioning all those non-existent lines which are made to appear real, so compelling as well as appalling. It is a postcolonial-postmodernist dialogue between the 'real' and the 'virtual' as in postmodernist discourse, or 'real' and the 
'imaginary' in terms of postcolonial diaspora. How much can one believe in these nonexistent lines that demarcate the regions called 'mine' and 'others'. Perceived from the global perspective, the dialogue immediately deconstructs all the meta-narratives pertaining to the nationalist constructions of the world. As exhibited in the following passage:

The narrator's grandmother in The Shadow Lines exemplifies nationalist attitudes towards time and space. She passionately values the idea of a national tradition ... Linked to this history teacher's idealization of tradition is her naive faith in national borders. Not realising that borders in maps are conventional constructions, she wonders when she flies back to her home in East Pakistan like "the long black line with green on one side and scarlet on the other... in a school atlas." ("The Contradictory Sexual Politics of The Shadow Lines", pp. 117-18)

Can one trust the demarcations made out of defined territories? In the later stage of postcolonial-postmodernist world where the boundaries of the nations appear shattering down, one is robbed of one's beliefs in one's nationalist culture. The whole experience seems disarming and weakening in which a major part of one's 'self' formulated by immediate cultural forces appear cracking down. The text of the novel reconstructs the shadow lines drawn on the map calling into question the very veracity of those defined lines. It throws back to the defined domains of human psyche. Evoking a corollary, it draws the segmented psychological realms of human mind. But, how far even these cerebral lines are to be trusted? Don't these also reproduce the feigned image of shadow lines in one's 'self'? Being constituted of the multiple impressions of 'otherness' which assimilate in the formulation of the 'self, how can one rely only on one's own 
history or celebrated nationalist culture of first phase of postcolonial for define one's 'self'? Tidib's model symbolises this distrust:

If in a Cartesian epistemological model, the observing subject disinterestedly observes the object, and if in one version of nationalist epistemology, historical knowledge is material that is appropriated for the national good, in Tridib's model, the observing subject is unmanned by his desire for the otherness of knowledge. ("The Contradictory Sexual Politics of The Shadow Lines" p. 123)

The narrative of the novel is built out of an intricate, constantly crisscrossing web of memories of many people. It invites the reader to invent an embedded spokespersonship, drawing out of the memories of those involved. Presenting a dialogue among the memories that hold mirrors of differing shades to the same experience, it reflects how the dialogic 'self' expresses itself out of a precarious negotiation of 'real' and 'virtual' on the one hand and 'real' and 'imaginary' on the other. The dialogue lies in weaving the discourse making use of the impressions accumulated and assorted at the level of collective consciousness.

\section{Conclusion}

In fact, living in today's era means living with differences and dissensions, which doubt the very foundation of the existence of these differences. Postcolonial-postmodernist literary discourses bring out the characters which represent this tendency of subversion. They appear grappling with the inner dissensions especially when found themselves standing in negotiated zones. It is the dialogic zone constituted of either the multiple viewpoints 
of the 'self' or the contradictory traits of multiple cultural constructions. As a $21^{\text {st }}$ century world citizen, one may feel the affinity with the characters like Balram, Tridib or the middle class growing boy narrator of Ghosh's The Shadow Lines, who defy the stability of monologue. At the same time formulating and resisting their own parameters, they rebel against any kind of 'fixity'. It subverts the very idea of the 'definite'. Their emotional and ideological dilemma represent the postcolonial-postmodernist psychology which questions various social and cultural norms evoking a dialogue between freedom and restrictions, ethical and unethical, individual and social, and real and 'virtual' versus real and 'imaginary'. It is an everlasting quest for refined version of human civilisation that can reflect the true spirit of the postcolonial-postmodernist world. As reflected in the post 1950s Indian fiction, it always evokes a dialogue posing some very essential questions regarding the contemporary reality:

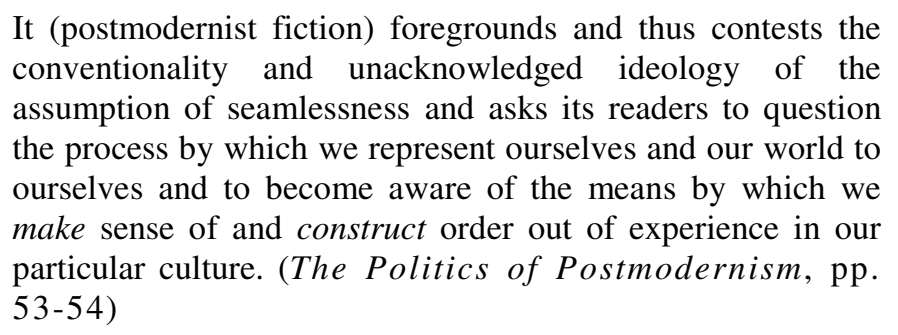

Indeed, as above quoted words reveal, it is simply the short term representations that assume any sense or order realised by one at individual or collective level. In today's world of negotiating differences, it always remains impossible to reach to the final resolution that can assert of monologic unity. Bakhtin's disclaiming of the possibility of finalisation enunciates the open 
ended nature of the dialogue. It may disappoint one but an assumption of paving way to a unified systematically structured realisation of complete 'self' is merely a deception. Hence the postcolonial-postmodernist 'self' is bound to remain floated. Affirming finality through accepting the possibility of unity being materialised through transcending differences somewhere will betray the true psychological underpinnings of new world.

\section{References}

Adiga, Arvind. The White Tiger. New Delhi: Harper Collins, 2008. Print.

Baker, Stephen. The Fiction of Postmodernity. Ediburgh: Edinburgh University Press, 2000. Print.

Bakhtin, Mikhail. The Dialogic Imagination: Four Essays. Austin: University of Texas Press, 1992. Print.

The Dialogical Imagination. ed. and trans. C. Emerson and M. Holquist. Austin: University of Texas P, 1981

Speech Genres and Other Late Essays. Trans. Vern W. McGee. Austin, TX: University of Texas Press, 1986. Print.

_Problems of Dostoevsky's Poetics. trans. C. Emerson. Minneapolis: University of Minnesota Press, 1984.

Da Silva, Stephen. “'Tridib's Gastric': The Contradictory Sexual Politics of The Shadow Lines". Postcolonial Indian Fiction in English and Masulanity. Ed. Rajeshwar Mittapalli and Letizia Alterno. New Delhi: Atlantic Publishers, 2009. Print.

Ghosh, Amitav. The Shadow Lines. New Delhi: Penguin Books, 1988. Print.

Hutcheon, Linda. The Politics of Postmodernism. London: Routledge, 1989. Print.

Wright, Richard. Native Son. New York: Perennial, 2003. Print. 